\title{
Group Maintenance Behaviors of Core and Peripherial Members of Free/Libre Open Source Software Teams
}

\author{
Michael J. Scialdone, Na Li, Robert Heckman, and Kevin Crowston \\ Syracuse University School of Information Studies \\ Hinds Hall, Syracuse, NY, 13244 USA \\ \{mjsciald, rheckman, crowston asyr. edu \\ http://floss.syr.edu
}

\begin{abstract}
Group Maintenance is pro-social, discretionary, and relation-building behavior that occurs between members of groups in order to maintain reciprocal trust and cooperation. This paper considers how Free/libre Open Source Software (FLOSS) teams demonstrate such behaviors within the context of email, as this is the primary medium through which such teams communicate. We compare group maintenance behaviors between both core and peripheral members of these groups, as well as behaviors between a group that remains producing software today and one which has since dissolved. Our findings indicate that negative politeness tactics (those which show respect for the autonomy of others) may be the most instrumental group maintenance behaviors that contribute to a FLOSS group's ability to survive and continue software production.
\end{abstract}

\section{Introduction}

Free/libre Open Source Software (FLOSS) is software developed and maintained by individuals working closely together in globally-distributed environments [5]. The FLOSS development communities can include dozens, hundreds or even thousands of volunteers who, for the most part, are not employed by and do not receive profits from the projects [20]. In community-based FLOSS, there are rarely explicit deliverables when developing software, and often no project plans or preset schedules [13]. These groups are "largely self-organizing, without formally appointed leaders of indicators of rank or role" [5] (p. 565). Rather, individuals choose to participate how they want to [13]. While there are groups of members who have a higher level of discretion on projects (those we refer to as core members), "power" is generally shared among individuals with the interest and skill to be contributors, allowing them to voice suggestions, contribute directly to the code repository, and distribute releases [5]. Those without such privileges we refer to as peripheral members. These members are still important, as they provide bug reports, documentation, user help and other important functions for projects.

FLOSS development presents a major deviation from traditional models of product development [1], where rewards for membership are usually more clearly defined. As 
opposed to being assigned to the team by a common manager, FLOSS members usually volunteer to participate (which Stark [18] described as a "heterarchy"). Despite this unconventional model of software development, FLOSS has enjoyed success, with a user base in the millions that includes major industries [4]. Therefore, it is important to understand how members of a FLOSS team maintain their groups. In other words, how does a FLOSS team maintain cohesion in an environment where tasks and direction is ambiguous and the rewards for participation are not obvious?

This paper considers one potential element that may be a factor in the cohesion of these virtual teams, namely, group maintenance behavior. Group maintenance behavior refers to the pro-social, discretionary and relation-building behaviors between members that maintain reciprocal trust and cooperation [16]. To describe the behaviors embedded in group maintenance, we draw on two closely related prosocial, organizational theories: social presence [8, 17]; and face work in computermediated communications (CMC) [15], both of which are explicated below.

The purpose of the research we present in this paper is to assess group maintenance behaviors both within and between two separate FLOSS teams: one which continues development today (Gaim, now named Pidgin), and one which has ceased production (Fire). To address this, we have performed both content analysis and statistical analyses of emails from the archives of these groups. These teams were purposely chosen as ideal contrasts as both teams worked on similar projects - multi-protocol instant messaging clients. We examine two research questions:

- Do group maintenance behaviors differ between the core and peripheral members of an ongoing FLOSS development team and one which ceased production?

- Do group maintenance behaviors differ between all participants of an ongoing FLOSS development team and one which has ceased production?

Our paper begins by presenting a review of the two theories we have drawn upon to explain group maintenance. We follow this by describing our method, including data collection techniques, our approach to content analysis, and our subsequent statistical analyses. We then discuss our results and the implications of our findings. Lastly, we discuss the limitations of our research, and provide recommendations for future research in this area.

\section{Theory}

In this section, we review the two theories that we have leveraged to describe group maintenance behavior: social presence theory, and face theory.

\subsection{Social Presence}

Garrison et al. [8] explain that social presence is a tactic that participants in a community use "to project their personal characteristics into the community" (p. 89), in other words, behaviors that are enacted in order to convey the sense of being a 'real person'. The feeling that participants in a virtual team or community are real has been linked to the success and cohesion of such teams [19]. When individuals can project emotions into a social setting, the group interactions may become more engaging and 
appealing to participants, thus delivering more intrinsic rewards to members [17]. Because face-to-face settings more easily establish social presence through visual and aural cues, members of virtual teams have to find methods to compensate [8].

Social presence is usually most easily established in the absence of ambiguous and equivocal informational cues [21]. Daft and Lengel [6] discuss how the informational bandwidth of media dictates the social cues that are able to be presented. They assert that rich media, such as face-to-face or telephony decrease ambivalence because of participants' ability to leverage paralinguistic cues, and natural language, with faceto-face being richest because one can easily include visual cues in expressing a message. Lean media, such as computer-mediated communication, is limited in ability to transfer multiple types of cues may lack the ability to convey clarity in message transmission [21].

Virtual teams communicate through the lean media of CMC, such as email, where text is the primary vehicle. As such, participants may attempt to increase social presence by enacting strategies that compensate for those cues that are unable to be expressed in the low informational bandwidth [8]. Such strategies include use of emoticons, vocatives, phatics, inclusive pronouns, complimenting, expressing appreciation, agreement, punctuation, and capitalization [17].

\subsection{Face Theory}

With references to the work of Goffman (1959, 1967, 1983), Morand [14] explains that face is "the positive value individuals claim for the public self they present" (p. 545). In other words, face can be viewed as an individual's public identity. Holtgraves notes that this is something that is held as scared to people, and is thus inherently vulnerable to each party who engages in interaction [11], meaning that people usually strive to maintain both their own face and that of others [14]. Because anyone's face can only be validated by others, it becomes within everyone's interest to maintain the face of those they interact with [11]. Face is therefore viewed as "a social rather than a psychological construct" [10] (p. 142). Thus, people tend to engage in social behaviors and actions that preserve, bolster, or show consideration for the face of others [14].

There are two desires of identity that make up this notion of face: the need for validation (also known as positive face) and the need for autonomy of action (also known as negative face) [12]. Examples of each come from Duthler, who writes that positive face is exemplified by the want of respect, membership in a valued community, and a reputation for competence and fairness; while negative face is exhibited by want to be left alone, independence from others, self direction, and freedom from restrictions created by others [7].

Politeness is a tool that individuals can use to moderate any face threats in communicating with others [14]. Despite the need to support the face of others, instances may sometimes occur when one has to "make requests, disagree, and offer advice or criticism to others" [7] (p. 3). Such instances are known as face threatening acts (FTAs), and can threaten both positive and negative face [12]. As members of groups strive to complete tasks and achieve shared goals, face may play an important role in maintaining cooperation, cohesion, and success. The politeness tactics with 
which participants manage face is potentially a key element in the understanding of group maintenance.

Politeness, as adapted for our conceptualization of group maintenance, is a linguistic act that can take the form of either positive tactics (to encourage positive face) or negative tactics (to encourage negative face) [15]. Examples of positive politeness tactics include use of colloquialisms or slang, vocatives, agreement, and inclusive pronouns. Examples of negative politeness include use of hedges, apologies, formal verbiage, and disclaimers [15, 14].

\section{Method}

In this section, we discuss our research design, data collection strategy, and analysis techniques. This study employs a multiple case study method, as we compare two FLOSS groups that developed multi-protocol Instant Messaging (IM) clients: Gaim and Fire. Both projects sought to deliver a unified platform for those users of multiple IM clients. Instead of having to be logged onto several clients at once, a user of a multi-protocol IM client can log onto a single program (such as Fire or Gaim) and have the other IM clients interface through the single one. These two projects were chosen for comparison because of similarities in their project goals, and nature of group tasks.

Gaim has emerged as a more effective project, based on Crowston et al.'s multivariate measure of effectiveness in FLOSS contexts [3]. Evidence of Gaim's success can also be seen in that the project is still on-going, while Fire ceased active development in early 2007. Of note, shortly after our data collection, Gaim was renamed Pidgin. However, in this paper, we refer to the project as Gaim as this was the name of the project when our data was collected.

\subsection{Data Collection}

For this research project, we analyzed email messages that were sent to both Fire's and Gaim's email lists by all contributors between June 2002 and February 2006, covering 45 months. Since most FLOSS activities (if not all) are archived, we were able to collect our data from the public email archives of both projects. Our data corpus was a convenience sample that had been previously collected for other studies conducted by authors of this paper. This was comprised of decision-making episodes, that is, sequences of email messages that begin with a trigger (an opportunity for choice), discussion related to the issue, and a decision announcement concerning the stated opportunity.

These decision-making episodes were originally sampled to observe potential changes in decision-making processes and norms over time. As such, 20 episodes from three similar time periods for each project were chosen, totaling 120 episodes. Drawn from the developers' mailing lists, the beginning and ending periods consisted of the first and last observable 20 decision episodes respectively. The middle period for each was comprised of 20 episodes that surrounded a major project release that fell approximately halfway between the beginning and ending periods. 
Table 1. Group Maintenance Indicators

\begin{tabular}{|c|c|c|}
\hline $\begin{array}{l}\text { Indicator } \\
\text { Category }\end{array}$ & Indicator & Definition \\
\hline \multirow{3}{*}{$\begin{array}{l}\text { Emotional } \\
\text { Expressions }\end{array}$} & Emoticons & $\begin{array}{l}\text { Expressions of emotion or emphasis using } \\
\text { emoticons }\end{array}$ \\
\hline & Capitalization & $\begin{array}{l}\text { Expressions of emotion or emphasis using } \\
\text { capitalization }\end{array}$ \\
\hline & Punctuation & $\begin{array}{l}\text { Expressions of emotion or emphasis using } \\
\text { punctuation such as exclamation points, } \\
\text { underlining, italic fonts, etc }\end{array}$ \\
\hline \multirow{9}{*}{$\begin{array}{l}\text { Positive } \\
\text { Politeness }\end{array}$} & Colloquialisms/Slang & $\begin{array}{l}\text { Use of colloquialisms or slang beyond group } \\
\text { specific jargon }\end{array}$ \\
\hline & Vocatives & $\begin{array}{l}\text { Referring to specific participant or addressing } \\
\text { an individual directly }\end{array}$ \\
\hline & Inclusive pronouns & Incorporating writer and recipient(s) \\
\hline & Salutations/Closings & $\begin{array}{l}\text { Personal greetings and closures for purely } \\
\text { social reasons }\end{array}$ \\
\hline & Complimenting & $\begin{array}{l}\text { Complimenting others or message content } \\
\text { beyond agreement }\end{array}$ \\
\hline & Expressing agreement & Expressing agreement with others \\
\hline & Apologies & Apologizing for one's own personal mistakes \\
\hline & $\begin{array}{l}\text { Encouraging } \\
\text { participation }\end{array}$ & $\begin{array}{l}\text { Encouraging all the members of the group to } \\
\text { participate }\end{array}$ \\
\hline & $\begin{array}{l}\text { Expressing } \\
\text { appreciation }\end{array}$ & $\begin{array}{l}\text { Showing appreciation for another person's } \\
\text { actions or work }\end{array}$ \\
\hline \multirow{4}{*}{$\begin{array}{l}\text { Negative } \\
\text { Politeness }\end{array}$} & $\begin{array}{l}\text { Disclaimers/Self- } \\
\text { depreciation }\end{array}$ & $\begin{array}{l}\text { Use of disclaimers prior to an FTA; self- } \\
\text { depreciation as a distancing tool; may include } \\
\text { apologies as explanations }\end{array}$ \\
\hline & Rational for FTA & $\begin{array}{l}\text { Stating an FTA as a general rule to minimize } \\
\text { impact or as to not single out an individual; } \\
\text { Explaining the reasons behind an action that } \\
\text { might threat someone's face. }\end{array}$ \\
\hline & Hedges/Hesitation & $\begin{array}{l}\text { Use of words/phrases/subjunctives to diminish } \\
\text { force of act; Use of hesitation in disagreement } \\
\text { (i.e. "well...") }\end{array}$ \\
\hline & Formal verbiage & Using formal wording choices \\
\hline
\end{tabular}

As a precautionary measure to ensure validity in our sample, a correlation analysis was conducted on our measures of group maintenance density (described in detail in section 4) by comparing the 120 decision-making episodes with approximately 300 random messages for each group that were not included in our episodic data. These analyses allowed us to determine that there was no statistically significant difference in group maintenance behavior densities between these two contexts. For this paper, we chose to focus only on the decision-making episodes because of the range of interaction that occurs when an opportunity for the group to make a decision about a feature, bug, or other task is at hand, and for the degree of input that is provided from both core and peripheral members in such episodes [9]. 


\subsection{Analysis}

We began by conducting content analysis to determine the extent of group maintenance behavior within both projects. Our coding scheme was created deductively from the literature we drew upon to describe group maintenance. It was first used to code a small number of messages in both projects by two graduate students working independently. Based on their discussions and agreement rates, the scheme was revised and then used to code more messages and revised again following additional discussions. This process repeated until we reached a relatively solid coding scheme. The final coding scheme is displayed below in Table 1 including definitions.

To avoid disproportionate representations from codes that implied a small unit of analysis such as emoticons or punctuation, and those that implied larger units such as rationale for FTA and encourage participation, we adopted a thematic measure as our unit of analysis. This is defined as a single idea or unit that conveys a single piece of information extracted (or the smallest unit of independent meaning) [2]. Such units vary in size from a single mark of punctuation to a word to multiple sentences when appropriate.

Table 2. Group Maintenance Indicator Densities

\begin{tabular}{|c|c|c|c|c|c|c|c|}
\hline $\begin{array}{l}\text { Indicator } \\
\text { Category }\end{array}$ & Indicator & $\begin{array}{l}\text { Fire } \\
\text { Core }\end{array}$ & $\begin{array}{l}\text { Fire } \\
\text { Peri }\end{array}$ & $\begin{array}{c}\text { Gaim } \\
\text { Core }\end{array}$ & $\begin{array}{c}\text { Gaim } \\
\text { Peri }\end{array}$ & $\begin{array}{c}\text { Fire } \\
\text { Total }\end{array}$ & $\begin{array}{l}\text { Gaim } \\
\text { Total }\end{array}$ \\
\hline \multirow{4}{*}{$\begin{array}{l}\text { Emotional } \\
\text { Expressions }\end{array}$} & Emoticons & .53 & 1.06 & 1.55 & 2.42 & .77 & 2.01 \\
\hline & Capitalization & .78 & .38 & 1.60 & .81 & .60 & 1.17 \\
\hline & Punctuation & 2.29 & 1.82 & 2.89 & 3.05 & 2.08 & 2.97 \\
\hline & Category Total & 3.60 & 3.26 & 6.04 & 6.27 & 3.45 & 6.16 \\
\hline \multirow{10}{*}{$\begin{array}{l}\text { Positive } \\
\text { Politeness }\end{array}$} & $\begin{array}{l}\text { Colloquialisms/ } \\
\text { Slang }\end{array}$ & 2.58 & 3.31 & 4.02 & 5.33 & 2.92 & 4.72 \\
\hline & Vocatives & 7.08 & 2.35 & 6.96 & 3.76 & 4.90 & 5.25 \\
\hline & Inclusive pronouns & 10.28 & 1.10 & 9.75 & 2.55 & 6.05 & 5.90 \\
\hline & $\begin{array}{l}\text { Salutations/ } \\
\text { Closings } \\
\end{array}$ & .90 & 2.02 & .57 & 4.25 & 1.41 & 2.54 \\
\hline & Complimenting & .25 & .43 & .98 & .49 & .33 & .72 \\
\hline & $\begin{array}{l}\text { Expressing } \\
\text { agreement }\end{array}$ & .90 & .38 & 1.91 & .76 & .66 & 1.29 \\
\hline & Apologies & .20 & .24 & .10 & .31 & .22 & .22 \\
\hline & $\begin{array}{l}\text { Encouraging } \\
\text { participation }\end{array}$ & 1.51 & 1.06 & 1.39 & 1.57 & 1.30 & 1.49 \\
\hline & $\begin{array}{l}\text { Expressing } \\
\text { appreciation }\end{array}$ & .86 & 1.73 & .46 & 1.48 & 1.26 & 1.01 \\
\hline & Category Total & 24.57 & 12.62 & 26.16 & 20.51 & 19.07 & 23.13 \\
\hline \multirow{5}{*}{$\begin{array}{l}\text { Negative } \\
\text { Politeness }\end{array}$} & $\begin{array}{l}\text { Disclaimers/Self- } \\
\text { depreciation }\end{array}$ & .98 & 1.58 & 1.19 & 2.69 & 1.26 & 1.99 \\
\hline & Rational for FTA & 1.23 & .67 & 1.19 & 1.39 & .97 & 1.29 \\
\hline & Hedges/Hesitation & 17.40 & 9.79 & 14.03 & 16.66 & 13.90 & 15.44 \\
\hline & Formal verbiage & .49 & .10 & .36 & .54 & .31 & .46 \\
\hline & Category Total & 20.10 & 12.14 & 16.77 & 21.27 & 16.44 & 19.18 \\
\hline
\end{tabular}


The two coders on this project were trained to code independently and then discuss any disagreements in order to reach consensus. They demonstrated an inter-rater reliability of .85 shortly prior to reaching the halfway mark in the data. Therefore they were allowed to code the remaining data independently.

\section{Findings}

The 60 Gaim episodes were coded with a total of 1965 group maintenance indicators; while the 60 Fire episodes were coded with 1732 indicators. However, early reviews of our data revealed that frequency counts were often misleading. For example, a group maintenance indicator that was observed once in an episode with a low word count would carry with it the same weight as that same indicator being observed once in an episode with a high word count. This signaled to us that a direct comparison of code frequencies between Fire and Gaim could be potentially misleading. As such, we decided to use a measure of density in order to normalize our data. We calculated density of group maintenance behaviors by considering how frequently these indicators were assigned per 1000 words. Hence, density (D) is defined by the number

Table 3. Results of Mann-Whitney U Tests on Group Maintenance Indicators and Categories

\begin{tabular}{|c|c|c|c|c|}
\hline $\begin{array}{l}\text { Indicator } \\
\text { Category }\end{array}$ & Indicator & $\begin{array}{c}\text { Fire Core } \\
\text { and Periphery } \\
\text { Comparison }\end{array}$ & $\begin{array}{c}\text { Gaim Core } \\
\text { and Periphery } \\
\text { Comparison }\end{array}$ & $\begin{array}{c}\text { Fire and } \\
\text { Gaim } \\
\text { Comparison }\end{array}$ \\
\hline \multirow{4}{*}{$\begin{array}{c}\text { Emotional } \\
\text { Expressions }\end{array}$} & Emoticons & -.75 & -1.30 & $-2.36^{*}$ \\
\hline & Capitalization & -.85 & $-2.02 *$ & -.84 \\
\hline & Punctuation & -.25 & -1.61 & -.57 \\
\hline & Category Total & -.58 & -1.46 & $-2.01 *$ \\
\hline \multirow{10}{*}{$\begin{array}{l}\text { Positive } \\
\text { Politeness }\end{array}$} & $\begin{array}{l}\text { Colloquialisms/ } \\
\text { Slang }\end{array}$ & $-2.03 *$ & -1.55 & -.10 \\
\hline & Vocatives & $-4.28 * * *$ & $-2.65 * *$ & -.41 \\
\hline & Inclusive pronouns & $-6.86 * * *$ & $-3.37 * * *$ & -1.23 \\
\hline & $\begin{array}{l}\text { Salutations/ } \\
\text { Closings }\end{array}$ & -1.79 & $-5.91 * * *$ & $-2.27 *$ \\
\hline & Complimenting & -.92 & -1.35 & -1.30 \\
\hline & $\begin{array}{l}\text { Expressing } \\
\text { agreement }\end{array}$ & -.68 & $-2.16^{* *}$ & -1.52 \\
\hline & Apologies & -.45 & -1.09 & -.98 \\
\hline & $\begin{array}{l}\text { Encouraging } \\
\text { participation }\end{array}$ & -1.03 & $-2.31 *$ & -.86 \\
\hline & $\begin{array}{l}\text { Expressing } \\
\text { appreciation }\end{array}$ & -1.14 & $-2.62 * *$ & -1.05 \\
\hline & Category Total & $-3.58 * * *$ & -.65 & -.50 \\
\hline \multirow{5}{*}{$\begin{array}{l}\text { Negative } \\
\text { Politeness }\end{array}$} & $\begin{array}{l}\text { Disclaimers/Self- } \\
\text { depreciation }\end{array}$ & -1.51 & $-1.96^{*}$ & -.50 \\
\hline & Rational for FTA & -.06 & -.41 & -.28 \\
\hline & Hedges/Hesitation & $-2.18 *$ & -1.70 & $-2.64 * *$ \\
\hline & Formal verbiage & $-2.44 *$ & -.76 & -1.25 \\
\hline & Category Total & -1.32 & $-2.42 *$ & $-2.74 * *$ \\
\hline
\end{tabular}

$* \mathrm{p}<.05 * * \mathrm{p}<.01 * * * \mathrm{p}<.001$ 
of codes in a message (c) divided by the number of words in the episode (w) multiplied by 1000 . Our formula can be represented as such:

$$
\mathrm{D}=1000(\mathbf{c} / \mathrm{w})
$$

Table 2 lists the densities of each group maintenance indicator and category for both core and periphery members of Fire and Gaim, as well as total densities across all members.

\subsection{Comparison of Group Members and Projects}

We performed Mann-Whitney $U$ tests on all group maintenance indicators and categories, comparing these between core and peripheral members for each group, and between all members of both groups. This nonparametric test was chosen as our research questions asked if the populations under scrutiny were inherently different. Table 3 lists the $\mathrm{z}$ scores resulting from our analyses, and significance is marked is with stars.

\section{Discussion}

At the beginning of this paper we posed two separate research questions. Our first question was: do group maintenance behaviors differ between the core and peripheral members of an ongoing FLOSS development team and one which ceased production? For both Fire and Gaim, emotional expressions indicated no statistically significant results, with the exception of capitalization within Gaim $(\mathrm{z}=-2.02, \mathrm{p}<.05$ with an average rank of 61.11 for core and of 52.05 for periphery). These results lead us to suspect that since emotional expressions are tactics that convey a sense of "realness" between members of a group, group-wide norms may be established as to how much "realness" is necessary (or appropriate) to be conveyed under their specific work environment. As will be discussed below, there was a significant difference between Fire and Gaim, but not within the groups.

Positive politeness behaviors showed the most statistically significant results within both Fire and Gaim, however only Fire demonstrated significant results between core and periphery members under positive politeness as a category $(\mathrm{z}=-3.58, \mathrm{p}<.001$ with an average rank of 66.46 for core, and 42.86 for periphery). This suggests that members of Gaim felt a consistent sense of camaraderie, while the periphery in Fire may have felt isolated, or at least less comfortable in showing closeness to other members.

Of note, the indicators vocatives and inclusive pronouns showed statistical significance between both core and periphery members within each group. Vocatives were significant, $\mathrm{z}=-4.28, \mathrm{p}<.001$ with average ranks of 68.01 and 42.86 for core and periphery respectively in Fire, and significant, $\mathrm{z}=-2.65, \mathrm{p}<.01$ with average ranks of 64.49 and 48.79 for core and periphery respectively in Gaim. Inclusive pronouns were significant, $\mathrm{z}=-6.86, \mathrm{p}<.001$ with average ranks of 74.62 and 35.62 for core and periphery respectively in fire, and significant, $\mathrm{z}=-3.37, \mathrm{p}<.001$ with average ranks of 65.85 and 47.48 for core and periphery respectively in Gaim. These results are particularly interesting because both of these indicators relate to 
referencing others within the group (vocatives directly, and inclusive pronouns as a way of including the speaker and others). As evidenced by their average ranks, core members of both groups enacted these behaviors most heavily, suggesting that peripheral members in general do not feel as comfortable expressing a sense of belonging within their groups.

Further supporting evidence of Fire having less camaraderie is in the lack of statistical significance between core and periphery in regard to negative politeness behaviors. While both hedge/hesitation and formal verbiage showed statistical significance in Fire $(\mathrm{z}=-2.18, \mathrm{p}<.05$, and $\mathrm{z}=-2.44, \mathrm{p}<.05$ respectively $)$, the category as a whole did not. This suggests that both core and peripheral members use distancing strategies in their interaction in a fairly consistent manner. Gaim, however, did demonstrate significant difference between the use of negative politeness tactics between core and periphery, $\mathrm{z}=-2.42, \mathrm{p}<.05$, with average ranks of 48.95 and 63.78 respectively. We infer from this that the periphery felt more of a need to demonstrate respect for the autonomy of others, perhaps indicating that those less directly involved in the project, while still feeling like part of the group, felt more of a need to respect the autonomy of others than did the core.

The results of these analyses are unsurprising considering that Fire was the group that ceased production, while Gaim (under the moniker of Pidgin) continues production to this day. Positive politeness behaviors were more consistent in Gaim, while negative politeness was more consistent in Fire. This suggests that both a sense of camaraderie and respecting the autonomy of others are beneficial to the continued success of a FLOSS team.

Our second research question was as follows: Do group maintenance behaviors differ between the members of an ongoing FLOSS development team and one which has ceased production? This question asked us to compare the combined behaviors of core and peripheral members in Fire with those in Gaim. Unsurprisingly, two out of our three group maintenance categories showed statistically significant differences between Fire and Gaim.

Emotional expressions, although the most infrequently observed in our data, did show a statistically significant difference between Fire and Gaim, $\mathrm{z}=-2.01, \mathrm{p}<.05$ with average ranks of 53.64 and 66.25 respectively. These results suggest that members of Gaim more frequently expressed a sense of being "real people" than did members of Fire.

Considering Fire showed significantly different positive politeness behaviors between core and periphery, and the more consistent use of such behaviors between members of Gaim, it is somewhat surprising that this category did not prove to be statistically significant when comparing behaviors of all members between Fire and Gaim. In fact, out of the 9 positive politeness behaviors identified, only salutations/closing was significant $(\mathrm{z}=-2.27, \mathrm{p}<.05$ with average ranks of 52.92 and 66.97 for Fire and Gaim respectively). In light of the differences within groups, and the lack of variation between groups, we surmise that positive politeness as a valid indicator of group maintenance may be best considered when looking at the interplay between different roles within a group. As evidenced by our case, when there is significant variation between group members (in our case Fire), the high end of the variation (in our case the core) may compensate enough for the low end of the variation (in our case the periphery) whereas it evens out when considering them as a 
whole and comparing to another group that had no significant variation (in our case Gaim) between group members.

The difference between negative politeness behaviors observed in Fire and Gaim were statistically significant, $\mathrm{z}=-2.74, \mathrm{p}<.01$ with average ranks of 51.26 and 68.59 respectively. As suggested by table 3, this was largely due to hedges/hesitation which showed significance between Fire and Gaim, $\mathrm{z}=-2.64, \mathrm{p}<.01$ with average ranks of 51.58 and 68.28 respectively. Referring to table 2 , this behavior was the densest out of all of our group maintenance indicators, indicating that among both groups and roles, it is the most salient measure of group maintenance. Thus, it is not surprising to see a significant difference in its density between a group that has ceased production and one which continues today.

While analyses regarding our first question lead us to assert that that both a sense of camaraderie and respecting the autonomy of others are beneficial to the ongoing success of a FLOSS team, comparing a retired FLOSS team with an active team yielded slightly different results. Negative politeness emerged from our study as the strongest indicator of group maintenance as it showed statistically significant difference in comparing both group members and projects. This leads us to suspect that a group, such as Gaim, may have a higher chance of continuing production when members, especially peripheral members, demonstrate respect for the autonomy of others within the group. However, as a note of caution that is elaborated on in the section below, further research needs to be conducted in order to generalize these results to the wider corpus of FLOSS teams.

\subsection{Limitations and Future Work}

Admittedly, there are threats to the validity of the research we present above. Most notably, in regard to external validity, we recognize that our study may not be entirely representative of group maintenance within FLOSS teams as a whole. Fire and Gaim consist of only two out of hundreds of thousands FLOSS projects that have either existed, or continue production today. As such, they represent a very small sample from which to draw our conclusions from. Both projects are also from the same corpus of FLOSS projects, specifically universal instant messaging clients. It is possible that the patterns of group maintenance behaviors observed in these projects are not generalizable to the larger, diverse population of FLOSS projects throughout time.

To address this limitation, we are in the process of developing and refining automated coding tools with the assistance of the Center for Natural Language Processing at Syracuse University. Once complete, we hope to perform group maintenance content analysis on a much larger sample of projects both active and inactive. It is expected that such an analysis will be more generalizable to FLOSS groups as a whole.

The major internal threat to the validity of our study is that of our instrumentation. Our density measure was created as a way to normalize our data since messages that contain more words are likely to display more group maintenance behaviors. Density is a measure of group maintenance behaviors per every 1000 words. As such, episodes that contained a smaller number of messages, and thus fewer words, may have caused outliers in our data in that some indicators may have been overly misrepresented. 
Also, in regard to instrumentation, indicators such as complimenting, apologies, capitalization, rationale for FTA, and formal verbiage appeared so infrequently that we suspect they may not be sufficient indicators of the behavior. Meanwhile, other indicators, such as salutations/closings and appreciation are currently categorized under one category of politeness, but have been observed in such contexts that lead us to suspect they are not mutually exclusive from the other. Further investigation within our own data and other scholarly literature will be conducted to determine the best course of action regarding these indicators.

\section{References}

1. Bitzer, J., Schrettl, W., Schröder, P.J.H.: Intrinsic motivation in open source software development. Journal of Comparative Economics 35, 160-169 (2007)

2. Budd, R., Thorpe, R.K., Donohue, L.: Content analysis of communication. Macmilliam, New York (1967)

3. Crowston, K., Annabi, H., Howison, J., Masango, C.: Towards a portfolio of FLOSS project success measures. In: Workshop on Open Source Software Engineering, 26th International Conference on Software Engineering. Edinburgh (2004)

4. Crowston, K., Howison, J., Annabi, H.: Information systems success in free and open source software development: Theory and measures. Software Process-Improvement and Practice 11(2), 123-148 (2006)

5. Crowston, K., Wei, K., Li, Q., Eseryel, U.Y., Howison, J.: Self-organization of teams in free/libre open source software development. Information and Software Technology Journal, Special issue on Understanding the Social Side of Software Engineering, Qualitative Software Engineering Research 49, 564-575 (2007)

6. Daft, R.L., Lengel, R.H.: Organizational information requirements: Media richness and structural design. Management Science 32(5), 554-571 (1986)

7. Duthler, K.: The politeness of requests made via email and voicemail: Support for the hyperpersonal model. Journal of Computer-Mediated Communication 11(2), 500-521 (2006), http: / / jcmc.indiana.edu/vol11/issue2/duthler.html

8. Garrison, R., Anderson, T., Archer, W.: Critical thinking in a text-based environment: Computer conferencing in higher education. The Internet and Higher Education 2(2-3), 87-105 (2000)

9. Heckman, R., Crowston, K., Li, Q., Allen, E.E., Eseryel, Y., Howison, J., Wei, K.: Emergent decision-making practices in technology-supported self-organizing distributed teams. In: The International Conference on Information Systems (ICIS 2006), Milwaukee, WI, December 10-13 (2006)

10. Holtgraves, T.: The linguistic realization of face management: Implications for language production and comprehension, person perception, and cross-cultural communication. Social psychology quarterly 55(2), 141-159 (1992)

11. Holtgraves, T.: Social psychology, cognitive psychology, and linguistic politeness. Journal of Politeness Research. Language, Behaviour, Culture 1(1), 73-93 (2005)

12. Meier, A.J.: Passages of politeness. Journal of Pragmatics 24(4), 381-392 (1995)

13. Mockus, A., Fielding, R.T., Herbsleb, J.D.: Two case studies of open source software development: Apache and mozilla. ACM Transactions on Software Engineering and Methodology 11(3), 309-346 (2002) 
14. Morand, D.: Dominance, deference, and egalitarianism in organizational interaction: A sociolinguistic analysis of power and politeness. Organization Science 7(5), 544-556 (1996)

15. Morand, D.A., Ocker, R.J.: Politeness theory and computer-mediated communication: A sociolinguistic approach to analyzing relational messages. In: The 36th Hawaii International Conference on System Sciences (HICSS 2003) (2003)

16. Ridley, M.: The Origins of Virtue: Human Instincts and the Evolution of Cooperation. Viking, New York (1996)

17. Rourke, L., Anderson, T., Garrison, D.R., Archer, W.: Assessing social presence in asynchronous, text-based computer conferencing. Journal of Distance Education 14(2), 51-70 (1999)

18. Stark, D.: Heterarchy: Distributed authority and organizing diversity. In: Henry, I.C.J. (ed.) The Biology of Business: Decoding the Natural Laws of Enterprise. Jossey-Bass, San Francisco (1999)

19. Stein, D., Wanstreet, C., Glazer, H., Engle, C., Harris, R., Johnston, S., Simons, M., Trinko, L.: Creating shared understanding through chats in a community of inquiry. The Internet and Higher Education 10(2), 103-115 (2007)

20. Wu, C.G., Gerlach, J.H., Young, C.E.: An empirical analysis of open source software developers' motivations and continuance intentions. Information \& Management 44(3), 253-262 (2007)

21. Yoo, Y., Alavi, M.: Media and group cohesion: Relative influences on social presence, task participation and group consensus. MIS Quarterly 25(3), 371-390 (2001) 